\title{
Considerações sobre os desafios múltiplos da Ciência Aberta
}

\author{
Tiago Lima Quintanilha \\ OberCom, ISCTE-IUL, CIES-IUL \\ E-mail: Tiago.lima@obercom.pt
}

\begin{abstract}
Resumo
Este é um artigo que tem por objectivo perceber e dar resposta a um conjunto de desafios que começam a ser associados ao modelo de ciência aberta, depois do período de novidade com o surgimento do modelo de publicações electrónicas baseadas no peer-review, na primeira metade da década passada. $O$ facto de só recentemente se começarem a debater as implicações principais que colocam grandes interrogações ao que se pretende ao nível do modelo de ciência aberta, acaba por ter repercussões no iniciático estado da arte disponível. Ao longo deste texto faremos alusão ao percurso histórico do fenómeno a que se convencionou desig-

nar como ciência aberta, para de seguida elencarmos um conjunto de questões que conferem uma certa noção de volatilidade a este modelo de publicação científica, nomeadamente ao nível da sustentabilidade financeira dos centros de investigação que suportam as referidas publicações; a condição de informalidade e incumprimentos vários por parte dos facilitadores do processo; o conflito de expectativas; o perigo da indústria paralela e parasitária; a fraca uniformização de processos necessários ao modelo de boas práticas científicas; a produção em massa que gera problemas de validação e verificação, entre outros assuntos.
\end{abstract}

Palavras-chave: Ciência aberta; sustentabilidade; desafios.

\begin{abstract}
This article tries to understand and respond to a set of challenges that somehow appear to be associated with the Open Science model. After the new period that emerged from a concept of electronic publications based on peer reviewed rese-

arch, scientific community is now slowly but surely focusing on problems that pose significant challenges to the sustainability of the Open Science model. The fact that this is a recent discussion ends up having repercussions on the available ini-
\end{abstract}


tiatory state of the art. The paper starts with making reference to the historical background of the phenomenon that is conventionally designated as Open Science. Furthermore, it focuses on discussions about significant number of issues that confer a certain notion of volatility to this scientific publishing model, particularly in terms of its financial sustainability; the informality and multiple failures related to the evaluation process that happens to be called as the ineffectiveness of the facilitators; the danger of a parallel and parasitic industry; the poor standardization of necessary measures aiming to fulfill good scientific practices; the problem of mass production that leads to validation and verification problems; and among other topics.

Keywords: Open science; sustainability; challenges.

\section{Introdução}

O final da agenda europeia para o catching up, quando era óbvio o dé1 fice de plataformas competitivas, a declaração de Berlim (2003) permitiu formalizar a mudança do paradigma de construção científica, partindo da ideia de que a disseminação de conhecimento passaria por torná-lo disponível em larga escala. $\mathrm{O}$ movimento estabelecia quatro pontos essenciais: suporte às publicações em Open Access e apoio à investigação e publicação neste formato por parte de investigadores e bolseiros de investigação científica; apoio e estímulo à publicação, tirando partido de plataformas de largo alcance (Internet); apoio ao desenvolvimento de formas de avaliação em Open Access, por forma a garantir qualidade científica e boas práticas de produção de conhecimento; e o pressuposto de compensação menos focada na propriedade e direitos autorais, e mais em termos de prestígio e alcance da produção. $\mathrm{O}$ percurso não foi imediato. De conceitos iniciais, como ciber-ciência, ciberinfraestrutura, e-science, e-research, o trajecto feito levou-nos à designação hoje conhecida como Ciência Aberta (Open Science), numa lógica assente em dois pressupostos principais que passavam por reconhecer o obsoletismo de uma cultura académica tradicional, de conhecimento fechado, quase sigiloso, e o necessário surgimento de uma objectividade científica construída num formato comunitário de um universo de colaborações em rede, potenciadoras de uma cumulatividade mais rápida e minimizando mais eficazmente os perigos 
do conhecimento duplicado. Por outras palavras, o objectivo passava por reinventar uma estrutura anacrónica de produção-difusão de conhecimento, com fraco alcance, quase privada e auto-centrada, para uma estrutura descentralizada em dinâmicas horizontais de colaboração entre pares. (Castells, 2002). Yochai Benkler (2006) designava o processo como "peer-production".

\section{Enquadramento histórico}

Este tema não deve ser interpretado sem antes ser feita uma análise histórica. Porque perceber estas novas formas de fazer ciência é, primeiro do que tudo, falar dos processos e mecanismos facilitadores de tal mudança. É perceber o que se passa ou tem passado em termos de evolução tecnológica e as suas repercussões na forma de pensar e produzir conteúdos, bem como a importância daquilo a que se convencionou chamar de Sociedade da Informação na intermediação desta mudança. Pois bem, a sociedade da informação está inserida num processo de mudança em que as novas tecnologias são os principais facilitadores. Segundo o Livro Verde para a Sociedade da Informação em Portugal, este modelo de organização das sociedades assenta num modo de desenvolvimento social e económico onde a informação, como meio de criação de conhecimento, desempenha um papel preponderante na produção de riqueza e contribuição para o bem-estar e qualidade de vida dos cidadãos.

$\mathrm{O}$ avanço da sociedade da informação é a possibilidade de todos poderem aceder à informação produzida. Tal como descrita nos quadros de referência da UNESCO, "A Sociedade da informação é a pedra angular das sociedades do conhecimento". No fundo, a Sociedade da Informação é o veículo potenciador da transmissão de conhecimento, e, no caso das revistas electrónicas, materializadas numa plataforma de longo alcance, o modelo online é a condição máxima por que se regem a produção, revisão, divulgação e disseminação do conhecimento científico. E é aqui que surge a relação da Ciência Aberta com as questões levantadas para a Sociedade da Informação e suas bases tecnológicas, no sentido em que esta última surge como o facilitador da transição de uma ciência de publicação tradicional, auto-centrada e fechada, para uma ciência mais aberta, de consulta gratuita.

Em termos mais gerais, por assim dizer, e só para termos ideia da amplitude desta problemática, podíamos recordar a própria concepção da Agenda de Lisboa, numa altura em que, como já referido, a Europa começava a per- 
der terreno face aos Estados Unidos (início da década de 90), num período de fim do catching-up Europeu aos países mais desenvolvidos (Japão e EUA), tendo ficado claro que criar novas plataformas competitivas era fundamental para sustentar o modelo Europeu. A ideia passou então por preparar a transição para uma economia e uma sociedade baseadas no conhecimento, através da aplicação de melhores políticas no domínio da sociedade da informação e seu acesso generalizado, e da inovação e desenvolvimento tecnológico. Assim, "passou a ser claro que não era possível construir uma sociedade baseada no conhecimento sem uma política de investigação e desenvolvimento mais ambiciosa, que se pudesse aproximar daquela que era praticada pelo modelo americano. A razão era simples: apenas com a aposta nas I\&D passa a ser possível constituir uma fonte essencial de criação de conhecimento, que desempenhe um papel crucial na compreensão do mundo em que vivemos e também na melhoria da competitividade, da qualidade de vida, da coesão social e dos modelos de governação" (Rodrigues: 2009).

E como era percebida a ciência?

Para Cribb (2010), a ciência, na sua génese, incorporava o ideal de servir a humanidade, sendo indispensável ao progresso civilizacional, desde que os seus intervenientes se comprometessem com padrões éticos necessários. No entanto, ciência era poder e o sistema que contribuía para lhe dar forma visava não a partilha ou a igualdade, mas sim a sua exclusividade, domínio e propriedade. É aqui que entra a necessidade de partilha de conhecimento, factor que também está na génese do reinventar das formas de divulgação e disseminação do conhecimento científico, algo a que se convencionou chamar de processo de democratização da ciência (Cribb: 2010).

Como refere Daston (1999:91, citado por Cardoso e Jacobetty, 2010), “a ciência é composta por um conjunto de práticas sistemáticas de pesquisa e investigação que têm por objectivo a criação de conhecimento sobre a realidade. Na procura do conhecimento sobre a realidade, a conquista da objectividade científica é operada de forma comunitária, um universo de colaborações estimulado por melhorias nos meios de transporte e comunicação, criando as redes de observadores cada vez mais vastas e densamente relacionadas". Jankowski (2007) dizia então que a essência da ciência estava a mudar. Para Cardoso e Jacobetty (2010), "estas mudanças resultavam principalmente da utilização de redes electrónicas que facilitavam o contacto entre investigadores, e de unidades de computação com elevada capacidade de processamento e 
armazenamento, que passaram a permitir trabalhar grandes volumes de dados num curto espaço de tempo. Actualmente, componentes informáticos e das TIC estão integrados na maioria dos processos de produção e distribuição do conhecimento científico. Uma boa parte do trabalho científico mais comum tem suporte electrónico: elaboração de textos, comunicação entre cientistas, et cetera, são exemplos de tarefas onde a aplicação das novas tecnologias é generalizada. Conseguimos assim colmatar certas limitações técnicas que previamente impediam um dado progresso da Ciência. (...) A utilização da Internet e das TIC no trabalho científico começava a dar origem a transformações nas formas de fazer Ciência. As possibilidades de comunicação e transmissão de dados entre investigadores deram origem a novas formas de percepção sobre as possibilidades da Ciência e também sobre a sua missão. A problemática de abertura das ciências nascia como fruto deste novo contexto comunicacional." Os mesmos autores continuam, referindo que "as novas ferramentas disponibilizadas aos cientistas, principalmente através de plataformas na Internet, traziam alterações ao modelo de produção científica, permitindo, entre outras coisas, maiores níveis de colaboração, internacionalização, transparência e impacto do trabalho científico. Assim, a configuração de um novo modelo científico que surgia como potenciador de inovação, passava a ser alvo de interesse por parte de académicos, instituições e entidades governamentais. $\mathrm{O}$ modelo Open Science estruturava-se principalmente em três níveis: partilha de ferramentas de pesquisa; partilha de dados e partilha de acesso na forma de publicações. Ainda assim, o conceito, pelo menos em termos mais gerais, não era na altura inteiramente consensual, havendo por isso uma série de denominações criadas ao longo dos anos prévios, que mais não eram do que uma espécie de upgrade epistemológico de um acontecimento que se tornava cada vez mais evidente." (Cardoso e Jacobetty: 2010).

Nentwich (2005) começou por falar em Ciber-Ciência, para definir "toda a actividade de pesquisa académica e científica no espaço virtual gerado pela rede informática e pelas tecnologias avançadas de informação e comunicação no geral".

"Outra ideia avançada foi a de Atkins, que falava já numa ciber-infraestrutura que estava para a Economia do Conhecimento como as infra-estruturas modernas. Por outro lado, em 1999, falava-se de e-ciência, a ciência de larga escala que iria basear-se cada vez mais em colaborações globais distribuídas e possibilitadas pela internet. Já o termo e-research surgia como mais con- 
sensual nos meios académicos ligados às ciências sociais e humanidades que integravam as potencialidades da internet, hipertexto, visualização virtual e comunidades cibernéticas. (...) Chegou-se então ao conceito de abertura científica com maior abrangência e que passou a ser designado como Open Science, reflectindo a disponibilização dos vários produtos do processo de pesquisa, desde a fase de observação e recolha de dados, à sua forma final sob a forma de publicações. Estruturava-se também enquanto alternativa complementar à estratégia da propriedade intelectual relativa à produção e distribuição de informação, partindo do pressuposto de que a privatização de dados e informação tendia a atrasar o avanço científico, tal como o progresso económico e social. Este regime de propriedade conduzia a situações de escassez artificial, que poderiam ser eliminadas através das funcionalidades desenvolvidas no meio digital, em especial na internet (Cardoso e Jacobetty: 2010).

"Para Paul A.David (2003), a Ciência Aberta era vista como o modelo científico alternativo ao modelo de propriedade intelectual de alocação de recursos para produção e distribuição de informação, que dependia de um sistema de incentivos não mercantis. Segundo o autor, os custos de acesso impostos pelos detentores de direitos de propriedade intelectual sobre o conhecimento técnico e científico tinham consequências nefastas para programas de pesquisa exploratória, considerados vitais para a Economia do Conhecimento. A definição de Ciência Aberta, segundo J. Daniel Gezelter, prendia-se com a transparência na metodologia experimental, a disponibilização pública, com possibilidade de reutilização dos dados científicos; disponibilização pública e transparência na comunicação científica e utilização de ferramentas Web para facilitar a colaboração científica. (...) A competitividade e o secretismo que pautaram o trabalho científico em tempos pareciam já não se enquadrar nas novas visões da ciência de um número crescente de investigadores. A internet estava a tornar-se um suporte para os cientistas disponibilizarem notas laboratoriais e as primeiras descobertas, aumentando o ritmo de progresso científico e integrando uma dimensão de debate mais alargada. Estas novas práticas não se enquadravam na cultura académica tradicional, em que tipicamente o cientista trabalhava só e sem revelar os resultados até à sua publicação, sem aprofundar todos os detalhes do processo de pesquisa. Isto permitia-lhes disponibilizar os seus resultados e as suas notas laboratoriais para outros, em qualquer ponto do globo. Permitia também alargar o debate dentro e fora da 
academia, integrando contribuições e aumentando a possibilidade de interdisciplinaridade. (idem)".

A principal valência do modelo visava sobretudo colmatar aquilo a que Cribb (2010) designou por falhanço nos veículos de transmissão das conquistas tecnológicas, na medida em que o conhecimento científico duplicava a cada 5 anos, mas a sua distribuição encontrava barreiras que tornavam o seu alcance (num planeta de 7 biliões de habitantes) e distribuição duas perfeitas miragens, devido aos veículos de divulgação fechados característicos da ciência tradicional.

\section{A sustentabilidade do modelo e seus perigos crescentes}

1) A condição a montante e o desinvestimento em centros responsáveis pelas diferentes publicações periódicas em acesso aberto

Tudo era novidade no modelo de Ciência Aberta. Mais de uma década depois, as primeiras dúvidas, ou o perigo da insustentabilidade a prazo. Em primeiro lugar, nenhuma resistência ao modelo. Contudo, há sérias questões que poderão estar a levantar dúvidas quanto à sustentabilidade e essência desse mesmo modelo. Se pegarmos nos pontos de apoio à construção do manifesto, verificamos uma espécie de abrandamento na eficácia da acção e do alcance dos facilitadores, por assim dizer. Começando pelo primeiro ponto, e especificamente no caso português, existe como que uma resistência a nível macro, governativo, institucional, o que se quiser chamar, ao próprio modelo. E essa resistência é, primeiro que tudo, contraproducente. O momento inicial de ciência aberta, apoiado pela Fundação para a Ciência e Tecnologia, no formato de verba, fundo ou incentivo, deu lugar, no início desta década, a uma espécie de retrocesso radicado na ideia de que era necessário alocar os incentivos e verbas disponíveis, exclusivamente ao apoio à edição de publicações não periódicas. Incompreensivelmente, os recursos passaram a ser unicamente direccionados a um tipo de publicação (como as monografias) bastante mais próxima do modelo convencional de alcance mais curto, num revisitar do processo tradicional onde a impressão e o arquivo em estante são características mais óbvias. Os centros de investigação, grandemente responsáveis pela existência e gestão dos e-journals, num momento que, já por si, representava um desinvestimento dos fundos para a ciência, passaram a ter de incluir nos 
orçamentos anuais a cada vez maior despesa que este tipo de publicações periódicas suscitam. Dos processos de proofreading, passando pela formatação e edição de textos, bem como do arquivo online e aluguer de servidores, e terminando no escrutínio e exigências cada vez mais prementes dos múltiplos indexadores, com novas formas de tratamento de texto, muitos são os desafios que se vão colocando à existência destas revistas, no formato de ciência aberta, com a clara repercussão que, a prazo, todo este peso poderá assumir na descontinuidade de algumas publicações. E neste pressuposto, num momento de fracos recursos, só as publicações mais fortes irão resistir, na certeza de que um filtro criado por via da disponibilidade financeira das diferentes publicações, é um filtro que não redunda necessariamente em maior qualidade e que põe em causa as bases de sustentação do modelo de ciência aberta, segundo a máxima de democratização da ciência. 
Figura 1. Fundos de apoio à comunicação científica, dos quais não consta nenhuma referência às publicações periódicas de natureza científica, em processo contínuo e em modelo aberto

Fundo de Apoio à Comunidade Científica

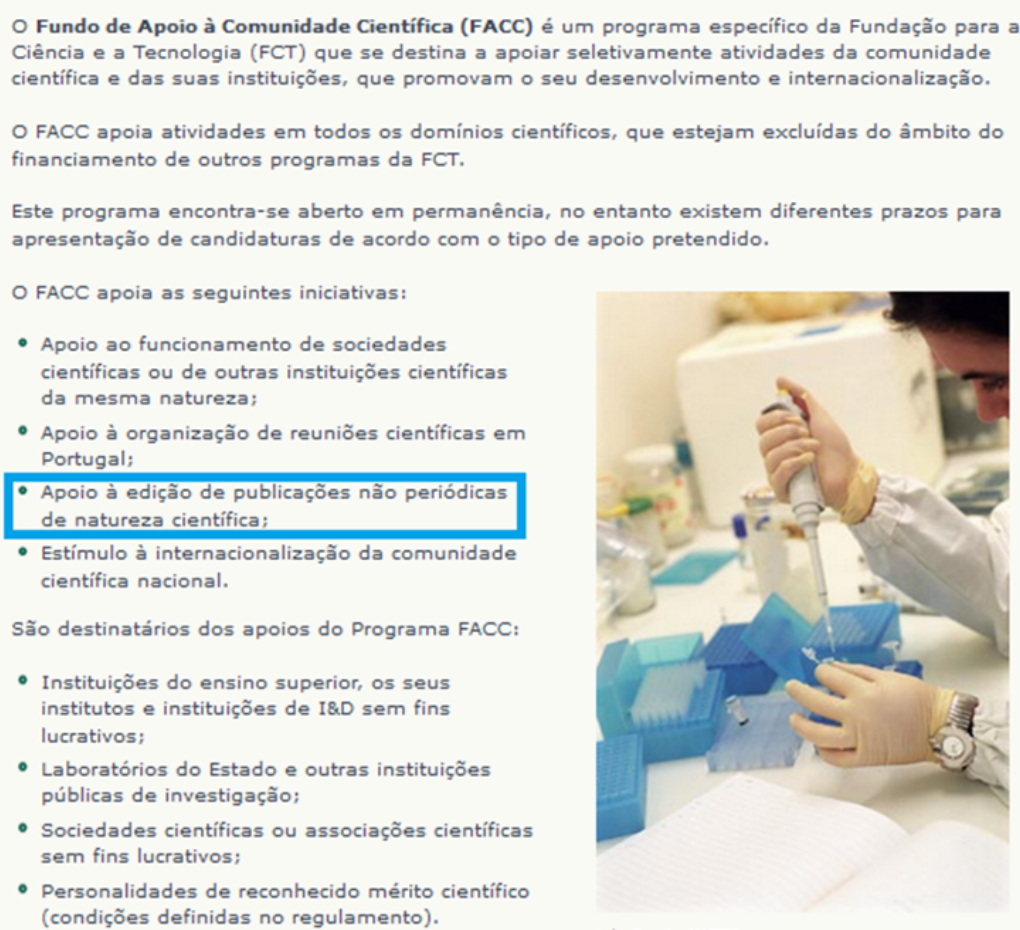

(condições definidas no regulamento).

Fonte: www.fct.pt

2) A falta de uniformização das avaliações e o perigo da arbitrariedade da decisão. O precário controlo da qualidade.

O segundo grande desafio reside no perigo que é olhar para a qualidade científica e as boas práticas de produção de conhecimento como metas adquiridas. O perigo aqui tem que ver com as próprias características do modelo e com a informalidade de todo o processo. Contudo, esta informalidade pode resultar em não comprometimento, algo que, numa revista em formato tradicional, sustentada por um corpo editorial de avaliação fixo, não sucede tão 
facilmente. Esta informalidade, traduzida em maior arbitrariedade nos processos de decisão e avaliação de artigos, consubstancia-se em resultados e em avaliações que não seguem um mesmo padrão, ou, por outras palavras, uma uniformização necessária que fica aquém, em múltiplos parâmetros de avaliação que diferem de artigo para artigo. Dito de outra forma, o problema maior reside no facto de um artigo A, com uma qualidade aceitável, ser preterido para um número de revista, por um artigo $\mathrm{B}$, de menor qualidade, sendo que o contexto aponta, vamos supor, para uma avaliação A que é minuciosa, exaustiva e actual, e uma avaliação B que é negligente, leviana e superficial. Ora, é aqui que entra a condição de informalidade e o perigo da não uniformização de processos. As agendas e as cargas de trabalho de professores e académicos tendem a encarregar-se deste fenómeno, no sentido em que, aliadas ao comprometimento da pessoa destacada para o processo de revisão, e a sua defesa, ou não, da causa, desempenham um quadro de volatilidade que se reflecte numa utopia do modelo avaliativo perfeito, capaz de premiar o mérito em função de uma escala decisória não sujeita a oscilações. Christopher Bare (2014), um dos grandes críticos do modelo, fala já do facto de o peer review ser um processo descompensado e ineficaz. Uma das razões também avançadas pelo autor, para o falhanço de uma avaliação eficaz, traduz-se na lentidão dos processos avaliativos, que redunda na facilidade com que alguns artigos acabam por ficar datados, mesmo aqueles que passam para uma fase de aceitação e edição. Para além disto, Priem (2012) refere que, na base do modelo avaliativo, está muitas vezes inculcada a ideia de olhar para o artigo apenas do ponto de vista do quão bem trabalhado este está metodologicamente, descurando a parte importantíssima de saber se o artigo terá um impacto significativo e potencial numa lógica de conhecimento cumulativo, pervertendo-se assim por completo, em muitos casos, o sentido do incremento do conhecimento como condição primária do processo avaliativo. Bare (2014) vai mais longe e sugere que, no sentido de validar a qualidade de cada artigo, deverá começar a surgir um processo duplo de revisão pós-publicação em combinação com alguma forma de filtragem algorítmica capaz de aferir a qualidade do artigo. Um processo que deve ser contínuo, portanto, na medida em que de um modelo de avaliação não uniformizado resultam perigos de desadequação dos momentos de decisão.

Para Casati (2006), há várias características associadas às revisões por pares, que podem levar a uma revisão enviesada. A saber: 1) por vezes, bons 
artigos são rejeitados em função de más revisões. A principal razão prende-se com o facto de uma avaliação baseada na rejeição do artigo ser uma avaliação fácil de fazer e que não necessita de grande elaboração. Por outro lado, as revisões são por vezes inconsistentes e as críticas feitas são por vezes opostas ao real conteúdo do artigo; 2) há avaliadores que, no geral, aplicam critérios baseados mais nos aspectos negativos e outros que se baseiam em aspectos mais positivos dos artigos. 3) muitas vezes, depois de uma revisão que até pode ser escrupulosa, os autores preocupam-se mais em adaptar e dar as voltas pedidas pelos revisores, do que propriamente trabalhar num contexto diferente capaz de dar resposta às principais dúvidas; 4) as diferentes revisões a cada artigo podem produzir comentários antagónicos, levando a uma maior dificuldade por parte dos autores em dar resposta às alterações pedidas.

3) A informalidade do processo e o perigo da falta de comprometimento por parte dos facilitadores do modelo

$\mathrm{O}$ terceiro grande perigo reside naquilo a que podemos designar como conflito de expectativas. Aqui não se trata de perceber que há diferentes percepções que são tão normais quanto saudáveis e que resultam de diferentes entendimentos de um mesmo artigo, por parte dos seus autores e dos avaliadores destacados para o processo de revisão. Esta é a parte benigna de todo o processo, mesmo em fenómenos de atrito mediado pelo corpo editorial da revista. $\mathrm{O}$ conflito de expectativas deve-se, isso sim, à celeridade exigida em cada processo de avaliação, muitas vezes contrária ao bom e regular funcionamento das publicações, e que não encontra correspondência na outra tarefa implícita a cada autor publicado. O perigo de perceber a publicação como prioritária e, em contrapartida, a avaliação como aspecto secundário ou até uma espécie de fardo. O perigo de não perceber que, em caso de dualidade e conflito de expectativas, a publicação alheia pode ser comprometida pela incapacidade que um autor publicado tem em perceber que um trabalho seu só foi efectivamente publicado, porque o avaliador destacado para o seu artigo se disponibilizou a desempenhar as duas fases vitais ao processo (chamemos-lhe defesa da causa). Pegando no exemplo anterior, se um autor A submete um trabalho A, é expectável que, a dada altura do seu ciclo de vida como utilizador da revista, este autor A seja convidado a decidir sobre a qualidade de um artigo nas áreas em que declaradamente fez formação e exerceu trabalho de investigação. E ao fazê-lo, deverá garantir que o segundo desafio já elen- 
cado, não se coloque, decidindo-se pelo desempenhar de uma avaliação clara e minuciosa do trabalho proposto para análise, e não pelo declinar da tarefa de revisão, assim tenha cumprido o desejo de publicar nessa revista. Por outras palavras, um modelo construído na lógica da publicação prioritária, em detrimento de uma avaliação tida essencialmente como sendo um aspecto secundário e quase descartável, é um modelo insustentável e um modelo que se traduz num aumento progressivo do volume de artigos em processo de avaliação que não são acompanhados pelo necessário número de avaliadores comprometidos com a revista. Em termos de comparação, podemos recordar o que se passa com os modelos de P2P. Neste modelo, há dois tipos de actores no desenrolar do processo. Em primeiro lugar, temos os seeders, aqueles que alimentam todo o fenómeno e que, em virtude da sua função de facilitadores, fazem chegar ao destinatário o conteúdo desejado, como é o caso de um filme, por exemplo. No lado oposto, temos a "sanguessuga" (que vem de leecher), no verdadeiro sentido da palavra, que equivale a dizer que é aquele que tira benefício do modelo em causa (neste caso, o acesso ao filme), mas que não contribui depois para o fenómeno da partilha. Esta "sanguessuga", depois do download e da visualização do filme, limita-se a classificar a experiência, ao limite, e a decidir-se pelo arquivo privado ou destruição do ficheiro em causa, quebrando ali a corrente de partilha do ficheiro conseguido por via de uma lógica altruística anterior. Ora, um autor publicado e reconhecido pela revista, que não está para grandes esforços no que à avaliação de artigos diz respeito, numa lógica declarada de não contribuição, não é mais do que uma "sanguessuga" a operar neste processo, beneficiando das grandes virtudes do modelo, mas escusando-se a ser parte integrante do mesmo. E num contexto hipotético de "sanguessugas" em larga escala, nenhum modelo erguido da construção entre pares poderá sobreviver. Este parece ser um ponto assente, de tal forma que o próprio programa da EU para a investigação e inovação refere que "alguns desafios precisam de ser tidos em conta, como direitos de propriedade intelectual, métricas alternativas, content mining, mas também desafios do foro inter-institucional, inter-disciplinar e colaboração internacional entre todos os actores envolvidos em investigação e inovação" (The EU framework programme for research and innovation: Horizon 2020).

4) Os parâmetros de decisão na escolha dos avaliadores. O perigo da flexibilização da escolha em função das necessidades da revista 
Este fenómeno adverso ao modelo foi já discutivo por Jason Priem e Bradley Hemminger (2012), quando se reportaram à ineficiência dos processos de avaliação, resultantes de uma incapacidade em seguir modelos de análise de perfis rigorosa, da parte dos policy-makers, baseada em rankings e listagens académicas necessárias no processo de escolha dos avaliadores.

Com efeito, o perigo da desordem da escolha, se assim quisermos chamar, está estreitamente relacionado com o segundo perigo já discutido, numa relação onde a montante temos o avaliador e a jusante o resultado da escolha do avaliador e do seu trabalho de avaliação. Trata-se de definir por que regras devemos cingir-nos aquando da escolha de um avaliador. O que é um avaliador referenciado? O que nos permite saber se o nome escolhido é adequado para a tarefa? Número de publicações? Número de anos de pesquisa naquela área específica? E qual o momento em que podemos assegurar que a pessoa escolhida cumpre os critérios mínimos para o desempenho da tarefa? Quão subjectiva é, por outro lado, essa análise curricular, e quão justa é, tendo em conta os padrões de avaliação usados na escolha de outros presumíveis avaliadores? Por outro lado, é exequível o controlo de todos os utilizadores que se auto-propõem à revista? E esse controlo deve ser desempenhado por quantos elementos do corpo editorial? Quão exequível é, do ponto de vista do gestor da revista, não perder o rasto a todos os processos, e ao mesmo tempo fazer encaminhar cada input aos elementos do corpo editorial? E que elementos do corpo editorial são esses? Quantos são? Quantos intervêm por decisão? Quão exequível é o papel de um gestor de revista, neste cenário de múltiplas exigências que vão da monitorização do status para cada artigo (revisões, re-submissões, edições, etc), ao contacto com as partes, em cada novo movimento registado na revista? E, num cenário de submissões várias, num aumento progressivo ao longo dos anos, quão limitativa pode ser a escolha dos avaliadores e qual o perigo de se recuar e flexibilizar os pressupostos que regulam a entrada de cada avaliador, por forma a aumentar o leque de escolhas capaz de manter a revista em fluxo contínuo? Estas são questões que terão de ser obrigatoriamente postas em perspectiva, durante cada processo de revisão, na medida em que é crucial, a montante, regular de forma cabal a escolha e a entrada dos avaliadores, como peças chave na definição da qualidade associada à revista. Para todos os efeitos, este é um problema característico das publicações online de largo espectro, algo que não se verifica, por exemplo, com revistas de curto alcance, de modelo tradicional, definido por um modelo 
fechado e restrito a um leque de nomes que compõem um corpo editorial e avaliativo fixos.

5) A indústria paralela lucrativa. O lado paradoxal da relação simbiótica com o indexador

O quinto problema está directamente relacionado com o primeiro problema denunciado. Num quadro de desinvestimento dos apoios a publicações de carácter periódico, e com a agudização das dificuldades dos centros de investigação que, regra geral, organizam e gerem as diferentes revistas em open access, torna-se difícil considerar as contínuas e necessárias exigências de indexadores, como um mal menor. Num contexto de racionalização de recursos, pelas razões já enunciadas, torna-se quase contraproducente entrar numa espiral de gastos cumulativos, conforme surgem novas directrizes para a aquisição de novos produtos que respondam às normas dos indexadores. Dos digital object identifiers, que muitas vezes pressupõem novos contratos para aquisição de serviços de inscrição e infraestruturas de identificação de conteúdos, passando pelo tratamento e formatação próprios dos conteúdos a registar nos indexadores, com novos programas como o Markup ou o Parser, entre imensos outros, que exigem por norma uma contratualização com um técnico exterior à revista, ou mesmo uma formação extra do responsável pela revista, muitas são as exigências que vão surgindo. Aqui, o problema maior reside na dificuldade que algumas revistas poderão sentir em manter-se em funcionamento, por duas razões essenciais: em caso de poderem dar resposta às exigências propostas, poderão colocar em causa a sustentabilidade da revista, em termos de verba necessária para o funcionamento da mesma, por mais pequena que seja; e em caso de não cumprimento com as alterações propostas, quaisquer que sejam, vêem a sua posição perante os indexadores sair prejudicada, podendo levar à sua exclusão e, ao limite, a uma certa ostracização da revista no meio e como que a uma imagem desacreditada num sector que é já por si bastante competitivo, podendo deixar de conseguir captar autores e artigos que possam garantir a periodicidade e a qualidade da revista.

6) A indústria parasitária

O sexto grande problema reside no perigo que a indústria parasitária de ciência representa. Ao longo dos últimos anos, questões como o rapto de revistas e os pedidos de aquisição de publicações, quase como se de OPAs 
lançadas se tratasse, têm sido uma constante. A título de exemplo, a revista OBS*Observatorio, propriedade do Observatório da Comunicação, tem sofrido constantes e crescentes pressões externas para libertar a revista a supostos actores que têm como fim último aglutinar o maior número de publicações periódicas possível, quase numa lógica de rapto, assumindo o ónus e responsabilidade de todas as decisões que, dali para a frente, possam vir a ser tomadas no quadro das revistas. E, como é óbvio, questões como a qualidade da revista, os direitos autorais previamente acordados, ou mesmo a lógica do interesse público, como grande bandeira do modelo de ciência aberta, ficariam irremediavelmente comprometidos num fenómeno evidente de mercantilização da coisa pública. Além do mais, a evidente ausência/degradação do modelo de financiamento para publicações deste tipo, mais não faz do que alimentar esta lógica de comportamento, no sentido em que muitas entidades responsáveis por publicações neste modelo, na ausência de qualquer tipo de financiamento, podem ver-se na iminência de decidir entre entregar a propriedade da revista, ou o descontinuar forçado dos volumes, por falta de verbas capazes de fazer face às despesas correntes relacionadas com o proofreading, edição de texto, entre outros gastos correntes.

Figura 2: exemplo de tentativa de aquisição de uma revista de publicação periódica e indexada

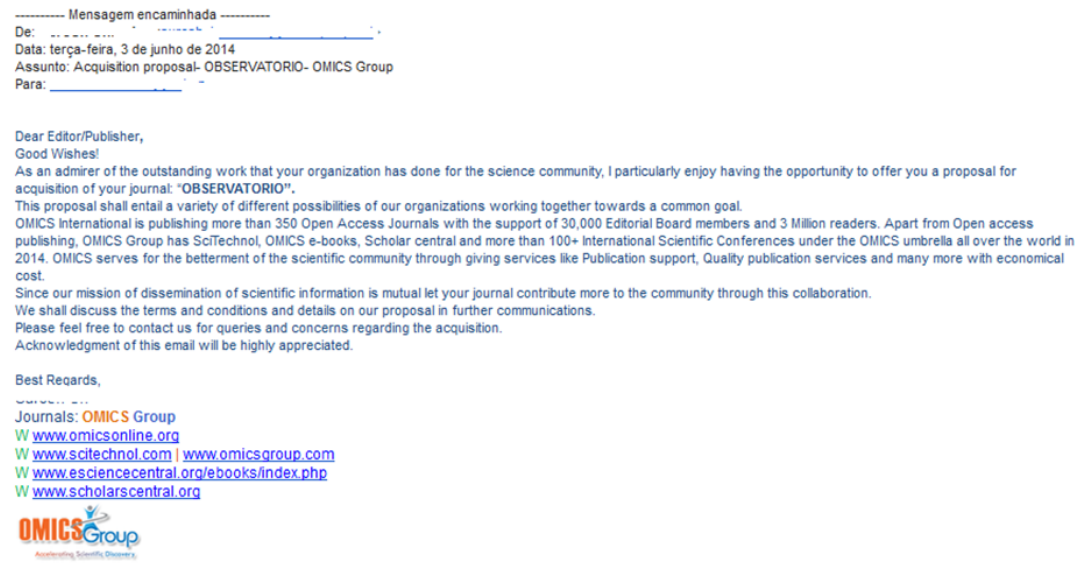


Outros perigos resultantes da ciência parasitária resultam dos jornais e publicações falsos ou clonados, capazes de baralhar um pouco a questão da oferta e o que é ou não real.

Outras questões, como a criação de corpos editoriais falsos, que de certa forma vão no sentido de legitimar a revista, dando-lhe capital simbólico, são igualmente um dos aspectos a ter em conta. Ora, é aqui que um indexador assume o seu papel mais relevante, no sentido em que permite estabelecer uma espécie de filtro que regula a entrada daquilo que é tóxico e separa o que é bom e construtivo, daquilo que é mau e destrutivo. No entanto, a própria existência e condição do indexador gera perturbação no funcionamento de uma revista, no sentido em que mexe com coisas tão primárias como a própria condição de existência da revista, ao nível da agilização dos recursos, podendo, com as exigências crescentes, asfixiar publicações e os respectivos centros de investigação que as gerem, passando a seguir um caminho que é de diferenciação, mas uma diferenciação que já não se enquadra no critério único da qualidade dos conteúdos publicados por cada revista.

Este é talvez o maior paradoxo na necessária simbiose entre a revista e o respectivo indexador. Dito de outra forma, ao mesmo tempo que um indexador, com as suas avaliações feitas às revistas que se propõem entrar nas suas bases de dados, estabelece como critério máximo de entrada a qualidade, por outro lado, e à medida que essa revista vai integrando os registos do indexador, já depois de concluído o processo de avaliação, vão sendo exigidas cada vez mais regras à sua continuação. E estas regras, que muitas vezes não vinham definidas aquando da integração da revista no referido indexador, acabam por limitar a própria reacção da revista, no sentido em que esta poderá não ter condições para dar resposta às novas exigências que vão surgindo, pondo definitivamente em causa a sua continuidade no indexador, com todos os efeitos nefastos de descredibilização que tal acontecimento acarreta. É certo que um indexador reserva para si, em qualquer momento, o direito a uma nova reavaliação baseada em novos pressupostos que venham a integrar nos seus estatutos, contudo, estas exigências crescentes pouco mais fazem do que alimentar uma indústria paralela de novos actores que entram no processo e que, em última análise, lucram com contratos paralelos sustentados na premente necessidade de novos critérios de formatação de textos, novos identificadores de conteúdo, entre outros assuntos, mesmo quando todas as revistas já incorporam códigos numéricos em identificadores (ISSN), ou mesmo quando a formatação dos 
textos já seguia anteriores critérios definidos por indexadores, critérios esses que, diga-se, até podem variar de indexador para indexador. Como combate a este tipo de indústria paralela e lucrativa, começam a surgir alguns movimentos que visam uma clarificação do modelo, no sentido em que lhe dão mais transparência. Um exemplo claro é o Centro para a Ciência Aberta, nos EUA, que foi fundando em 2013 e tem como objectivo principal contribuir para a abertura, integridade e reprodução da pesquisa científica, tirando partido de um trabalho conjunto de várias comunidades científicas que tentam produzir ferramentas e serviços válidos e gratuitos que reforcem as práticas e valores da pesquisa científica.

7) O perigo da produção em descontrolo

O modelo de ciência aberta, zeitgeist no processo de publicação científica, apesar de bem implementado e aceite em larga escala por um grande número de comunidades científicas, não goza necessariamente de uma aquiescência adquirida e universal. Existem modelos de construção de narrativas, por parte de académicos, que explanam de certa forma os grandes erros e perigos do modelo. Esta desacreditação, sustentada no entendimento dos grandes desafios relacionados com o modelo, alguns deles estando na génese da construção do próprio modelo (como a questão da informalidade), poderão, a prazo, levar a um percurso de desacreditação do modelo. Apesar de os focos principais de cepticismo não integrarem ainda as condições de falha (em alguns casos do foro logístico) inerente ao próprio modelo, como as anteriormente evidenciadas, o que é certo é que o ataque tem vindo a ser assinalável, começando desde logo pela própria noção de credibilidade. E um modelo que é visto como que passando por processos de validação redutores, comprometendo na sua génese justificativas metodológicas da neutralidade axiológica, é um modelo que, no seu percurso, irá deparar-se com resistências várias. Uma dessas resistências, ponto de base para a crítica de Cristopher Bare em "Guide to Open Science" (2014), é a confirmação de um modelo que perpetua o aumento da escala de produção da ciência, em níveis desmesurados que colocam em causa a eficaz regulação dos conteúdos produzidos e a necessária validação/verificação desses conteúdos por parte da academia. Num certo sentido, a noção de que tudo é publicável e replicável, beneficiando de um paradigma com fraquezas mais ou menos óbvias, reproduz a ideia de que é necessária maior reflexividade e o reinventar de um modelo baseado numa ciência mais refractária e na objecti- 
vidade do conhecimento, capaz de resistir ao lado destruidor de uma produção em massa, em descontrolo e em permanentemente desregulação.

Tabela 1. síntese dos pontos discutidos

Ameaças

1) O paradoxo de um sistema de indexação que promove indústrias paralelas de serviços pagos

2) Indústria parasitária

3) Insustentabilidade financeira dos centros de investigação aos quais estão associadas grande parte das publicações

\section{Pontos fracos}

1) A informalidade do modelo e o fraco comprometimento pelos facilitadores do processo

2) Processos de avaliação nãouniformizados e de validação precária

3) A vulnerabilidade à indústria do rapto e donagem de revistas

\section{Oportunidades}

1) Novos sistemas de colaboração inter-institucional, inter-disciplinar e inter-pares que reforcem a exequibilidade do modelo de Ciência Aberta e combatam o parasitismo paralelo ao modelo (ex: COS - Center for Open Science)

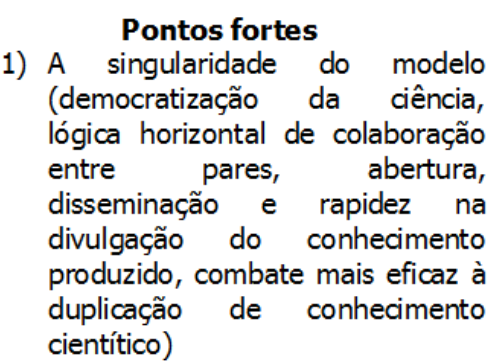

Fonte: elaboração própria

\section{Pistas para estudos futuros}

Como já sublinhado, o estudo dos desafios e perigos do modelo de ciência aberta é ainda relativamente recente, pelo que importará conhecer com mais detalhe a perspectiva de múltiplos actores no processo, sejam eles avaliadores, gestores e coordenadores editoriais de revistas, ou mesmo pessoas ligadas aos vários indexadores.

$\mathrm{O}$ argumento actual ainda se centra muito nas potencialidades e alcance do modelo e na forma como veio permitir a disseminação e divulgação de conteúdo científico necessário, mas a verdade é que não houve ainda um debate amplo ao nível das suas limitações, sendo que estas limitações, como vimos anteriormente, são muitas e afectam diversas áreas do processo de gestão das revistas. 
Neste sentido, e numa lógica exploratória, tentámos compreender, dentro de uma rede próxima de contactos, quais os principais receios e perigos percepcionados na gestão diária das revistas. Estes testemunhos foram recolhidos num contexto de troca de mensagens electrónicas, e respeitando o pedido unânime dos respondentes no necessário anonimato da divulgação das respostas. Foram colocadas três questões a pessoas associadas a indexadores e uma questão apenas a seis coordenadores de revistas editoriais em acesso aberto.

Quatro coordenadores de revista deram resposta ao pedido, ao passo que os outros dois optaram por não responder. Foram também contactadas 4 pessoas associadas aos indexadores, mas apenas uma respondeu ao pedido.

As opiniões recolhidas são elucidativas dos desafios percepcionados por intervenientes privilegiados no processo, em especial aqueles que estão directamente associados às revistas. A visão da pessoa ligada aos indexadores é talvez mais moderada e aponta para um quadro em que as revistas não deixaram ainda de cumprir com as exigências propostas, mesmo que as afirmações produzidas não invalidem propriamente o facto de estas revistas estarem a sentir mais dificuldades. Para estes respondentes, a conclusão a tirar é que as obrigações crescentes não colocaram ainda em causa o funcionamento das revistas associadas, descurando a ideia de que estas exigências têm surgido em modo cumulativo, característica que poderá assumir maiores repercussões no futuro próximo.

A questão colocada aos quatro gestores de revista foi a seguinte: Quais os principais desafios que, nas suas tarefas de gestão de revista, considera mais relevantes e que poderão pôr em causa a própria sustentabilidade da revista? (atrasos em revisões, exigências crescentes de indexadores, avaliadores registados na revista que não dão seguimento às tarefas pedidas em tempo útil; etc)

Resposta Anónimo 1: "Os principais desafios à sustentabilidade da revista, no que diz respeito às tarefas de gestão, são a capacidade de mobilizar revisores em tempo útil e também as exigências crescentes das bases de indexação. No primeiro caso, não só é difícil conseguir a colaboração de revisores como o número dos que cumprem o pedido na data estipulada é muito reduzido, comprometendo a pontualidade da publicação. Penso que isso tem a ver com a sobrecarga a que estão su- 
jeitos muitos investigadores/docentes mas também a algum fechamento de classe, havendo competição em vez de cooperação entre profissionais da mesma área. No segundo caso, dou este exemplo: a publicação de um número, quando todos os elementos estão prontos e revistos, é coisa para demorar uma manhã de trabalho; a preparação dos mesmos conteúdos para os formatos exigidos por algumas bases é trabalho para uma semana, com sucessivas revisões e alterações. É um bocadinho a subversão do objectivo destas bases, que deveriam promover a visibilidade dos estudos publicados em vez de atolarem quem trabalha na divulgação científica em tarefas morosas, tecnicamente inflexíveis."

Resposta Anónimo 2: "A revista X, da qual sou coordenadora editorial, tem tido dificuldade em se indexar convenientemente devido à sua falta de periodicidade e isto deve-se a dois fatores: os autores e os revisores não cumprem os prazos nem as regras, alegando sempre a falta de tempo como se nós, editores, não tivéssemos também outras atividades."

Resposta Anónimo 3, relativamente à dificuldade em obter revisões em tempo útil: "É difícil e podia ser tão mais fácil se por vezes dissessem que não podem. Vale-nos a compreensão mútua e a colaboração de outros colegas, que compensam as impossibilidades e imprevistos."

Resposta Anónimo 4: While $Y^{1}$ journals are not in jeopardy of their sustainability, certainly one of the challenges are timely reviews."

As três perguntas colocadas a uma pessoa que desempenha trabalho num indexador, foram as seguintes:

Pergunta 1: Considera que as crescentes exigências por parte de alguns indexadores, poderão levar à exclusão de revistas de qualidade reconhecida, que, por uma questão de falta de recursos, não têm como fazer face a despesas extra decorrentes de novos requisitos e imposições?

Pergunta 2: Considera que já podemos referir com alguma propriedade que existe uma indústria paralela lucrativa a beneficiar da simbiose necessária entre revista e indexador?

Pergunta 3: Perante o crescimento da indústria parasitária (rapto de revistas, clonagem de revistas, clonagem de corpos editoriais, etc), quais pensa que serão as principais estratégias de um indexador para fazer face ao problema,

1. Y diz respeito ao nome de uma revista científica internacional em open access, com sede nos EUA. Para efeitos de anonimato, também a referência exacta à dita revista foi retirada. 
no curto prazo? Devem os indexadores intervir numa clarificação e ataque ao problema, junto dos incumpridores, ou este é apenas um problema que resulta da falta de regulação eficaz neste sector, não cabendo ao indexador a resolução deste tipo de problemas?

Resposta Anónimo 1: "A única coisa que posso transmitir é a nossa experiência relativamente à primeira questão. Apesar de termos aumentado as exigências, não houve até à data nenhuma revista que desistisse da $\mathrm{X}^{2}$ por incapacidade de dar resposta. Julgo que as revistas de qualidade reconhecida encontraram estratégias para se adaptarem às novas exigências. Por outro lado, revistas de menor qualidade e menos profissionalizadas terão mais dificuldade em conseguir a sua indexação em bases de dados."

\section{Referências bibliográficas}

Bare, C. (2014). The guide to Open Science. Disponível em: www.fosteropenscience.eu

Benkler, Y. (2006). The Wealth of Networks - How Social Production Transforms Markets and Freedom. Disponível em: http://hosamred.googlepages.com

Castells, M. (2002). A Era da Informação: economia, sociedade e cultura, Vol.1: A Sociedade em Rede. Lisboa: Fundação Calouste Gulbenkian.

Casati, F. et al (2006). Publish and perish: why the current publication and review model is killing research and wasting your money. Disponível em: http://eprints.biblio.unitn.it

Cardoso, G. \& Jacobetty, P. (2010). O que significa Open Science?. Disponível em: www.lini-research.org

Cribb, J. \& Sari, T. (2010). Open Science: Sharing knowledge in the global century. Australia: CSIRO Publishing.

Jankowski, N.W. (2007). Exploring e-science: An introduction. Journal of Computer-Mediated Communication, 12(2): 549-562. Disponível em: http://jcmc.indiana.edu

2. X diz respeito ao nome de um indexador/colecção de revistas e artigos científicos. Para efeitos de anonimato, também a referência exacta ao dito indexador foi retirada. 
Nentwich, M. (2005). Cyberscience: Modelling ICT-induced changes of the scholarly communication system. Information, Communication \& Society, 8(4): 542-560.

Priem, J. \& Hemminger, B. (2012). Decoupling the scholarly journal. Frontiers Computational Neuroscience, 6(19): 1-13. Disponível em: http://journal.frontiersin.org

Rodrigues, M.J. et al (2009). Europe, Globalization and The Lisbon Agenda. MA, USA: Edward Elgar.

The EU Framework Programme for Research and Innovation (Horizonte 2020): http://ec.europa.eu 